\title{
Impact of varying analytical methodologies on grain particle size determination
}

\author{
J. R. Kalivoda, * C. K. Jones, $\nmid$ and C. R. Stark ${ }^{1}$ \\ *Sparboe Farms, Litchfield, MN 55355; †Department of Animal Sciences and Industry, Kansas State University, \\ Manhattan 66506; and ‡Department of Grain Science and Industry, Kansas State University, Manhattan 66506
}

\begin{abstract}
The determination of particle size is an important quality control measurement for feed manufacturers, nutritionists, and producers. The current approved method for determining the geometric mean diameter by weight $\left(\mathrm{d}_{\mathrm{gw}}\right)$ and geometric standard deviation $\left(\mathrm{S}_{\mathrm{gw}}\right)$ of grains is standard ANSI/ASAE S319.4. This method controls many variables, including the suggested quantity of initial material and the type, number, and size of sieves. However, the method allows for variations in sieving time, sieve agitators, and the use of a dispersion agent. The objective of this experiment was to determine which method of particle size analysis best estimated the particle size of various cereal grain types. Eighteen samples of either corn, sorghum, or wheat were ground and analyzed using different variations of the approved method. Treatments were arranged in a $5 \times 3$ factorial arrangement with 5 sieving methods: 1) 10-min sieving time with sieve agitators and no dispersion agent, 2) 10-min sieving time with sieve agitators and dispersion agent, 3) 15-min sieving time with no sieve agitators or dispersion agent, 4) 15-min sieving time with sieve agitators and no dispersion agent, and 5) 15-min sieving time with sieve agitators and dispersion agent conducted
\end{abstract}

in 3 grain types (ground corn, sorghum, and wheat) with 4 replicates per treatment. The analytical method that resulted in the lowest $\mathrm{d}_{\mathrm{gw}}$ and greatest $\mathrm{S}_{\mathrm{gw}}$ was considered desirable because it was presumably representative of increased movement of particles to their appropriate sieve. Analytical method affected $\mathrm{d}_{\mathrm{gw}}$ and $\mathrm{S}_{\mathrm{gw}}(P \leq 0.05)$ measured by both standards. Inclusion of sieve agitators and dispersion agent in the sieve stack resulted in the lowest $\mathrm{d}_{\mathrm{gw}}$, regardless of sieving time. Inclusion of dispersion agent reduced $\mathrm{d}_{\mathrm{gw}}(P \leq$ 0.05 ) by 32 and $36 \mu \mathrm{m}$ when shaken for 10 and $15 \mathrm{~min}$, respectively, compared to the same sample analyzed without dispersion agent. The addition of the dispersion agent also increased $\mathrm{S}_{\mathrm{gw}}$. The dispersion agent increased the quantity of very fine particles collected in the pan; therefore, $\mathrm{S}_{\mathrm{gw}}$ was significantly greater $(P \leq 0.05)$. Corn and sorghum ground using the same mill parameters had similar $\mathrm{d}_{\mathrm{gw}}(P>0.05)$, but wheat ground using the same mill parameters was 120 to 104 $\mu \mathrm{m}$ larger $(P \leq 0.05)$ than corn and sorghum, respectively. Both sieve agitators and dispersion agent should be included when conducting particle size analysis. The results indicate that 10 and $15 \mathrm{~min}$ of sieving time produced similar results.

Key words: feed, grain, methodology, particle size analysis

(C) 2017 American Society of Animal Science. All rights reserved. J. Anim. Sci. 2017.95:113-119 doi:10.2527/jas2016.0966

\section{INTRODUCTION}

Research has demonstrated that swine feed efficiency is improved by $1.0 \%$ to $1.2 \%$ for every $100 \mu \mathrm{m}$ reduction in corn particle size or geometric mean diameter $\left(\mathbf{d}_{\mathbf{g w}}\right)$ ground with a hammermill (Wondra et al., 1995; De Jong et al., 2012; Paulk et al., 2015). Accurate particle size analysis is important to meet quality con-

\footnotetext{
${ }^{1}$ Corresponding author: crstark@ksu.edu

Received September 1, 2016.

Accepted November 3, 2016.
}

trol specifications in the feed mill, as well as compare samples across laboratories. However, allowable variations within the standard method used to determine the mean $d_{g w}$ can result in differences of up to 100 $\mu \mathrm{m}$ for the same sample. The current approved method used to determine $\mathrm{d}_{\mathrm{gw}}$ and the geometric standard deviation $\left(\mathbf{S}_{\mathbf{g w}}\right)$ of feeds and ingredients is described by standard ANSI/ASAE S319.4 (American Society of Agricultural and Biological Engineers [ASABE], 2008). This method controls many variables, including the suggested quantity of initial material and the type, number, and size of sieves. However, the method 
allows for variations in sieving time, sieve agitator inclusion, and the use of a dispersion agent. The most significant change in the standard method occurred between standards ASAE S319.2 (ASABE, 1995) and ANSI/ ASAE S319.3 (ASABE, 2007), when sieving time increased from 10 to $15 \mathrm{~min}$. Fahrenholz et al. (2010) suggested that the goal in particle size analysis is to find the lowest $\mathrm{d}_{\mathrm{gw}}$ and greatest $\mathrm{S}_{\mathrm{gw}}$. Both Fahrenholz et al. (2010) and Stark and Chewning (2012) reported that the addition of agitators and dispersion agent significantly changed the $\mathrm{d}_{\mathrm{gw}}$ of a ground sample of corn, but a direct comparison using different sieving times has not been reported in various grains. Therefore, the objective of this experiment was to determine which method of particle size analysis best estimates the particle size of various cereal grains. The hypothesis of this experiment was that the addition of both sieve agitators and a dispersion agent would result in a lower $\mathrm{d}_{\mathrm{gw}}$ of a sample, which would indicate a more accurate determination.

\section{MATERIALS AND METHODS}

Treatments were arranged in a $5 \times 3$ factorial arrangement with 5 sieving methods: 1) 10-min sieving time with sieve agitators and no dispersion agent, 2) 10 -min sieving time with sieve agitators and dispersion agent, 3) 15-min sieving time with no sieve agitators or dispersion agent, 4) 15-min sieving time with sieve agitators and no dispersion agent, and 5) 15-min sieving time with sieve agitators and dispersion agent conducted for 3 grain types (ground corn, sorghum, and wheat) with 4 replicates per treatment. A total of 360 particle size analytical procedures were conducted in this experiment, stemming from 18 different samples of ground grain. These samples represented 2 mill types (hammermill and roller mill) and 3 grind sizes (coarse, medium, and fine). Mill type and grind size were random variables. Samples were ground at the Kansas State University O. H. Kruse Feed Technology Innovation Center in Manhattan. The hammermill (model 22115, Bliss Industries, Ponca City, OK) was equipped with 1.59-, 4.76-, and 6.35-mm screens for fine, medium and coarse grinds, respectively. The roller mill (model 924, RMS Roller Grinder, Harrisburg, SD) rolls were 2.36 and 2.36, 4.72 and 5.51, and 6.30 and 7.09 corrugations/ $\mathrm{cm}$ roll on the top, middle, and bottom roll pairs, respectively. The hammermill screen sizes and roll gap settings were kept constant for each cereal grain. The differences in mill type and grind size were intended to create a robust set of ground grain samples.

Samples were divided using a riffle divider to obtain a sample size of approximately $100 \pm 5 \mathrm{~g}$. The weighed samples were then analyzed using different variations of the ANSI/ASAE S319.4 standard method
Table 1. Sieve and sieve agitator arrangement

\begin{tabular}{lcc}
\hline $\begin{array}{c}\text { U.S. sieve } \\
\text { number }\end{array}$ & $\begin{array}{c}\text { Sieve opening, } \\
\mu \mathrm{m}\end{array}$ & $\begin{array}{c}\text { Sieve } \\
\text { agitator(s) }\end{array}$ \\
\hline 6 & 3,360 & NONE \\
8 & 2,380 & NONE \\
12 & 1,680 & 3 rubber balls \\
16 & 1,190 & 3 rubber balls \\
20 & 841 & 3 rubber balls \\
30 & 595 & 1 rubber ball; 1 bristle sieve cleaner \\
40 & 420 & 1 rubber ball; 1 bristle sieve cleaner \\
50 & 297 & 1 rubber ball; 1 bristle sieve cleaner \\
70 & 210 & 1 rubber ball; 1 bristle sieve cleaner \\
100 & 149 & 1 bristle sieve cleaner \\
140 & 105 & 1 bristle sieve cleaner \\
200 & 74 & 1 bristle sieve cleaner \\
270 & 53 & 1 bristle sieve cleaner \\
Pan & - & None \\
\hline
\end{tabular}

for particle size analysis at the Kansas State University Swine Nutrition Laboratory. Particle size analysis was conducted with 2 stainless-steel sieve stacks (13 sieves) to prevent the residual dispersion agent present on the sieve from affecting subsequent samples without the dispersion agent. Both sieve stacks contained sieve agitators with bristle sieve cleaners and rubber balls measuring $16 \mathrm{~mm}$ in diameter (Table 1). The 15-min treatment without sieve agitators and no dispersion agent was analyzed in the sieve stack without dispersion agent. Sieves were cleaned after each analysis with compressed air and a stiff bristle sieve cleaning brush.

Each sieve was individually weighed with the sieve agitators to obtain a tare weight. The $100 \pm 5 \mathrm{~g}$ sample was then placed on the top sieve. If dispersion agent (model SSA-58, Gilson Company Inc., Lewis Center, $\mathrm{OH})$ was required $(0.5 \mathrm{~g})$, it was mixed by stirring to uniformly distribute the agent into the sample prior to placing the mixture on the top sieve. The sieve stack was then placed in the Ro-Tap machine (model RX-29, W. S. Tyler Industrial Group, Mentor, OH) and run for the specified time (10 or $15 \mathrm{~min}$ ). Once time had elapsed, each sieve was weighed with the sieve agitator(s) to obtain the weight of the sample on each sieve. The amount of material on each sieve was used to calculate $\mathrm{d}_{\mathrm{gw}}$ and $\mathrm{S}_{\mathrm{gw}}$. When a dispersion agent was used, its weight was not subtracted from the weight of the pan. ANSI/ASAE S319.4 states that the effect of the dispersion agent on particle size need not be considered, meaning that the low inclusion amount will not significantly impact the calculations even if all of the material reaches the pan. Calculations were performed according to the equations listed and described in ANSI/ASAE standard S319.4 (Eq. [1] to [4]) for $d_{\text {gw }}$ and $\mathrm{S}_{\mathrm{gw}}$ and ASAE standard $\mathrm{S} 319.2$ for $\mathrm{S}_{\mathrm{gw}}$ (Eq. [5]). 
Equations [6] and [7] depict how to calculate the range for $68 \%$ of the particles in a sample. Equation [6] uses $\mathrm{d}_{\mathrm{gW}}$ calculated with Eq. [1]. Equation [6] uses $\mathrm{S}_{\mathrm{gw}}$ calculated with Eq. [5], whereas Eq. [7] uses $\mathrm{S}_{\mathrm{gw}}$ calculated with Eq. [4].

$$
\mathrm{dgw}_{\mathrm{gw}}=\log ^{-1}\left[\frac{\sum_{\mathrm{i}=1}^{\mathrm{n}}\left(\mathrm{W}_{\mathrm{i}} \log \overline{\mathrm{d}}_{\mathrm{i}}\right)}{\sum_{\mathrm{i}=1}^{\mathrm{n}} \mathrm{W}_{\mathrm{i}}}\right],
$$

where $\mathrm{W}_{\mathrm{i}}$ is mass on the ith sieve $(\mathrm{g}), \mathrm{d}_{\mathrm{i}}$ is the nominal sieve aperture size of the ith sieve $(\mathrm{mm}), \mathrm{d}_{\mathrm{gw}}$ is the geometric mean diameter or median size of particles by mass $(\mathrm{mm})$ or geometric mean diameter or median size of particles on the ith sieve ( $\mathrm{mm}$ ) or Eq. [2], and $n$ is the number of sieves +1 (pan).

$$
\bar{d}_{i}=\left(d_{i} \times d_{i+1}\right)^{1 / 2}
$$

where $d_{i}$ is nominal sieve aperture size of the ith sieve $(\mathrm{mm})$ and $\mathrm{d}_{i+1}$ is the nominal sieve aperture size in the next larger than the ith sieve (just above in a set; $\mathrm{mm}$ ).

$$
\mathrm{S}_{\log }=\left[\frac{\sum_{\mathrm{i}=1}^{\mathrm{n}} \mathrm{W}_{\mathrm{i}}\left(\log \overline{\mathrm{d}}_{\mathrm{i}}-\log \mathrm{d}_{\mathrm{gw}}\right)^{2}}{\sum_{\mathrm{i}=1}^{\mathrm{n}} \mathrm{W}_{\mathrm{i}}}\right]^{1 / 2}=\frac{\mathrm{S}_{\mathrm{ln}}}{2.3},
$$

where $W_{i}$ is mass on the ith sieve $(g), d_{i}$ is the nominal sieve aperture size of the ith sieve $(\mathrm{mm}), \mathrm{d}_{\mathrm{gw}}$ is geometric mean diameter or median size of particles by mass $(\mathrm{mm})$ or geometric mean diameter or median size of particles on the ith sieve (mm) or Eq. [2], $\mathrm{S}_{\log }$ is the geometric standard deviation of the log-normal distribution by mass in a 10-based logarithm (dimensionless), $\mathrm{S}_{\ln }$ is the geometric standard deviation of the log-normal distribution by mass in a natural logarithm (dimensionless), and $\mathrm{n}$ is the number of sieves +1 (pan).

$$
\mathrm{S}_{\mathrm{gw}} \approx \frac{1}{2} \mathrm{~d}_{\mathrm{gw}}\left[\log ^{-1} \mathrm{~S}_{\mathrm{log}}-\left(\log ^{-1} \mathrm{~S}_{\mathrm{log}}\right)^{-1}\right]
$$

where $\mathrm{W}_{\mathrm{i}}$ is the mass on the ith sieve $(\mathrm{g}), \mathrm{d}_{\mathrm{i}}$ is the nominal sieve aperture size of the ith sieve $(\mathrm{mm}), \mathrm{d}_{\mathrm{gw}}$ is the geometric mean diameter or median size of particles by mass $(\mathrm{mm})$ or geometric mean diameter or median size of particles on the ith sieve $(\mathrm{mm})$ or Eq. [2], $\mathrm{S}_{\log }$ is the geometric standard deviation of $\log$ normal distribution by mass in a 10-based logarithm (dimensionless), and $\mathrm{S}_{\mathrm{gw}}$ is the geometric standard deviation of particle diameter by mass $(\mathrm{mm})$.

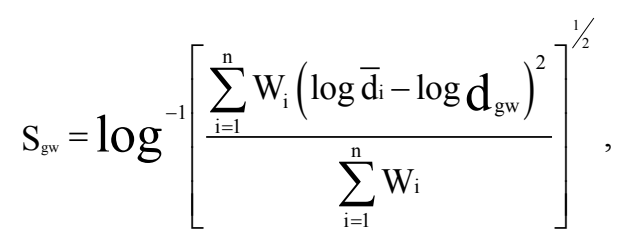

where $d_{i}$ is the nominal sieve opening of the ith sieve $(\mathrm{mm}), \mathrm{d}_{\mathrm{i}+1}$ is the nominal sieve opening in the next larger than the ith sieve (just above in a set; $\mathrm{mm}$ ), $\mathrm{d}_{\mathrm{gw}}$ is the geometric mean diameter by mass of the sample $(\mathrm{mm})$, $\mathrm{d}_{\mathrm{i}}$ is the geometric mean diameter of particles on the ith sieve (mm) or Eq. [2], $\mathrm{S}_{\mathrm{gw}}$ is the geometric standard deviation of the sample estimate by mass, $\mathrm{W}_{\mathrm{i}}$ is the mass on the ith sieve $(\mathrm{g})$, and $\mathrm{n}$ is the number of sieves +1 (pan).

$$
\frac{\mathrm{d}_{\mathrm{gw}}}{\mathrm{S}_{\mathrm{gw}}}={ }_{\text {lower limit, }} \mathrm{d}_{\mathrm{gw}} \times \mathrm{S}_{\mathrm{gw}}=\text { upper limit, [6] }
$$

where $68 \%$ of the particles are determined by finding the difference between the upper and lower limits using $\mathrm{S}_{\mathrm{gw}}$ from Eq. [3] and $\mathrm{d}_{\mathrm{gw}}$ is the geometric mean diameter or median size of particles by mass $(\mathrm{mm})$ or geometric mean diameter or median size of particles on the ith sieve (mm) or Eq. [2].

$$
\mathrm{S}_{\mathrm{gw}} \times 2=68 \% \text { of particles, }
$$

where $68 \%$ of the particles are determined using $\mathrm{S}_{\mathrm{gw}}$ from Eq. [4].

Analytical methods were chosen on the basis of the 5 most common variations currently used in the feed manufacturing industry. The change in the standard method that occurred between ASAE S319.2 and ANSI/ASAE S319.3 when sieving time increased from 10 to $15 \mathrm{~min}$ was not widely adopted by the feed industry and therefore was not included in the evaluation. These variations in the ANSI/ASAE S319 standard method were evaluated by versions ASAE S319.2 and ANSI/ASAE S319.4 for a method $\times$ grain type interaction effect and main effects for $\mathrm{d}_{\mathrm{gw}}$ and $\mathrm{S}_{\mathrm{gw}}$ for method and grain. Treatments were arranged in a $5 \times 3$ factorial arrangement with 5 sieving methods and 3 grain types: 1) 10-min sieving time with sieve agitators and no dispersion agent, 2) 10 min sieving time with sieve agitators and a dispersion agent, 3) 15-min sieving time with no sieve agitators and no dispersion agent, 4) 15-min sieving time with sieve agitators and no dispersion agent, and 5) 15-min sieving time with sieve agitators and a dispersion agent.

The 5 sieving methods were repeated 4 times for each of the 18 samples, comprising 3 grain types (corn, wheat, and sorghum), 2 mill types (hammermill and roller mill), and 3 grind sizes (coarse, medium, and fine) with a different technician conducting the procedure for each 
Table 2. Interaction effects of method $\times$ grain type on geometric mean diameter $\left(\mathrm{d}_{\mathrm{gw}}\right)$ and geometric standard deviation $\left(\mathrm{S}_{\mathrm{gw}}\right)^{1}$

\begin{tabular}{|c|c|c|c|c|c|c|c|}
\hline \multirow[b]{2}{*}{ Item } & \multicolumn{5}{|c|}{ Method } & \multirow[b]{2}{*}{ SEM } & \multirow[b]{2}{*}{$P$} \\
\hline & 1 & 2 & 3 & 4 & 5 & & \\
\hline Sieving time, min & $10 \mathrm{~min}$ & 10 & 15 & 15 & 15 & & \\
\hline Sieve agitator inclusion & Yes & Yes & No & Yes & Yes & & \\
\hline Dispersion agent inclusion & No & Yes & No & No & Yes & & \\
\hline $\mathrm{d}_{\mathrm{gw}}, \mu \mathrm{m}$ & & & & & & 225 & 0.172 \\
\hline Corn & 544 & 498 & 586 & 530 & 486 & & \\
\hline Wheat & 656 & 640 & 682 & 647 & 623 & & \\
\hline Sorghum & 559 & 524 & 577 & 551 & 512 & & \\
\hline \multicolumn{8}{|l|}{$\mathrm{S}_{\mathrm{gw}}, \mu \mathrm{m}$} \\
\hline ASAE S319.2 & & & & & & 0.32 & $<0.0001$ \\
\hline Corn & $2.20^{\mathrm{d}, \mathrm{e}}$ & $2.67^{\mathrm{a}}$ & $1.97^{\mathrm{f}}$ & $2.26^{\mathrm{c}, \mathrm{d}}$ & $2.69^{\mathrm{a}}$ & & \\
\hline Wheat & $2.26^{\mathrm{c}, \mathrm{d}}$ & $2.55^{\mathrm{b}}$ & $2.16^{\mathrm{e}}$ & $2.27^{\mathrm{c}}$ & $2.55^{\mathrm{b}}$ & & \\
\hline Sorghum & $2.24^{\mathrm{c}, \mathrm{d}}$ & $2.65^{\mathrm{a}}$ & $2.16^{\mathrm{e}}$ & $2.29^{\mathrm{c}}$ & $2.65^{\mathrm{a}}$ & & \\
\hline ANSI/ASAE S319.4, $\mu \mathrm{m}$ & & & & & & 117 & 0.931 \\
\hline Corn & 452 & 554 & 427 & 459 & 542 & & \\
\hline Wheat & 548 & 631 & 528 & 540 & 614 & & \\
\hline Sorghum & 455 & 552 & 448 & 462 & 545 & & \\
\hline
\end{tabular}

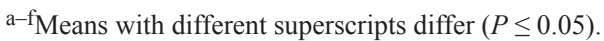

${ }^{1}$ A total of 360 particle size analytical procedures were conducted in this experiment, with 18 samples each of corn, sorghum, and wheat. Subsamples of each grain type were then analyzed using 5 different variations of the ANSI/ASAE S319.4 standard particle size analysis method. There were 4 replicates per method.

of the 4 replicates with random effects being grind size and mill type. Data were analyzed using the GLIMMIX procedure of SAS (SAS Inst. Inc., Cary, NC). Samples were blocked by day and technician. Interactions were removed from the model if $P>0.05$. Results were considered significant if $P \leq 0.05$ and a tendency if $0.05 \leq$ $P \leq 0.10$. Contrasts were used to evaluate differences in time (10 vs. $15 \mathrm{~min}$ ), sieve agitators, and dispersion agent. The least significance difference test was used to determine differences between sieving method and grain. The CORR procedure of SAS was used to determine Pearson correlation coefficients for $\mathrm{d}_{\mathrm{gw}}$ and $\mathrm{S}_{\mathrm{gw}}$ to compare when the dispersion agent was subtracted from the weight of the pan for each grain.

\section{RESULTS AND DISCUSSION}

Technician was intended to be a fixed effect in this experiment, but the variable was removed from the model because of insignificance for $\mathrm{d}_{\mathrm{gw}}(P>0.05)$ and $\mathrm{S}_{\mathrm{gw}}(P>0.05)$. The method $\times$ grain interaction for $\mathrm{d}_{\mathrm{gw}}$ $(\stackrel{P}{>}>0.05)$ was not significant (Table 2$)$. The method $\times$ grain interaction for $\mathrm{S}_{\mathrm{gw}}$ method ASAE S319.2 calculated with Eq. [5] was significant $(P \leq 0.05)$ because of the differences within each grain for each method. A similar trend among grain types was observed across all methods when $\mathrm{S}_{\mathrm{gw}}$ was calculated using method ASAE S319.2. The $S_{\mathrm{gw}}$ method ANSI/ASAE S319.4 calculated with Eq. [4] eliminated the method $\times$ grain type interaction $(P>0.05$; Table 2$)$, whereas main effects for method $(P \leq 0.05$; Table 3$)$ and grain $(P \leq$ 0.05 ; Table 4$)$ were significant. Differences were observed when $\mathrm{d}_{\mathrm{gw}}$ was evaluated for different ground grain types ( $P \leq 0.05)$. When compared to corn (529 $\mu \mathrm{m})$, the $\mathrm{d}_{\mathrm{gw}}$ of sorghum was $16 \mu \mathrm{m}(545 \mu \mathrm{m})$ larger, and wheat was $120 \mu \mathrm{m}(649 \mu \mathrm{m})$ larger $(P \leq 0.05)$.

The main effects of method and grain were significant for $\mathrm{d}_{\mathrm{gw}}(P \leq 0.05)$. The geometric mean diameter by weight was lowest when both sieve agitators and dispersion agent were included in the analysis. The addition of dispersion agent reduced the mean $\mathrm{d}_{\mathrm{gw}}$ by $32 \mu \mathrm{m}$ (586 to $554 \mu \mathrm{m})$ with a 10 -min sieving time $(P \leq 0.05)$. The addition of a dispersion agent with a 15 -min sieving time reduced the mean $\mathrm{d}_{\mathrm{gw}} 36 \mu \mathrm{m}$ (576 to $540 \mu \mathrm{m} ; P$ $\leq 0.05)$. However, the difference in $\mathrm{d}_{\mathrm{gw}}$ with increased sieving time from 10 to $15 \mathrm{~min}$ was not significant $(P$ $>0.05)$. Adding sieve agitators reduced $\mathrm{d}_{\mathrm{gw}}$ by $39 \mu \mathrm{m}$ $(615$ to $576 \mu \mathrm{m})$ with a 15 -min sieving time $(P \leq 0.05)$.

Research consistently has demonstrated the addition of sieve agitators and dispersion agent lower $\mathrm{d}_{\mathrm{gw}}$ and increase $\mathrm{S}_{\mathrm{gw}}$ (Goodband et al., 2006; Fahrenholz et al., 2010; Stark and Chewning, 2012). Woodworth et al. (2002) determined that the addition of sieve agitators resulted in a lower $\mathrm{d}_{\mathrm{gw}}$ and greater $\mathrm{S}_{\mathrm{gw}}$ because the sieve agitators broke up agglomerates and aided in the flow ability of the sample throughout the sieve stack. ASABE (2008) did not specify the type, number, or position of sieve agitators in the stack of sieves. 
Table 3. Main effect of analytical method on geometric mean diameter $\left(\mathrm{d}_{\mathrm{gw}}\right)$ and geometric standard deviation $\left(\mathrm{S}_{\mathrm{gW}}\right)$ of various grain types ${ }^{1}$

\begin{tabular}{|c|c|c|c|c|c|c|c|c|c|c|}
\hline \multirow[b]{2}{*}{ Item } & \multicolumn{5}{|c|}{ Method } & \multirow[b]{2}{*}{ SEM } & \multirow[b]{2}{*}{$P$} & \multicolumn{3}{|c|}{ Orthogonal contrasts } \\
\hline & 1 & 2 & 3 & 4 & 5 & & & Sieving time & Sieve agitators & Dispersion agent \\
\hline Sieving time, $\min$ & 10 & 10 & 15 & 15 & 15 & & & & & \\
\hline Sieve agitator inclusion & Yes & Yes & No & Yes & Yes & & & & & \\
\hline Dispersion agent inclusion & No & Yes & No & No & Yes & & & & & \\
\hline $\mathrm{d}_{\mathrm{gw}},{ }^{2} \mu \mathrm{m}$ & $586^{\mathrm{b}}$ & $554^{\mathrm{c}}$ & $615^{\mathrm{a}}$ & $576^{\mathrm{b}}$ & $540^{\mathrm{c}}$ & 223 & $<0.0001$ & 0.125 & $<0.0001$ & $<0.0001$ \\
\hline \multicolumn{11}{|l|}{$\mathrm{S}_{\mathrm{gW}} 3$} \\
\hline ASAE S319.2 & $2.23^{b}$ & $2.62^{\mathrm{a}}$ & $2.09^{\mathrm{c}}$ & $2.27^{\mathrm{b}}$ & $2.63^{\mathrm{a}}$ & 0.32 & $<0.0001$ & $<0.0001$ & $<0.0001$ & $<0.0001$ \\
\hline ANSI/ASAE S319.4, ${ }^{4} \mu \mathrm{m}$ & $485^{\mathrm{b}, \mathrm{c}}$ & $579^{\mathrm{a}}$ & $467^{\mathrm{c}}$ & $487^{b}$ & $567^{\mathrm{a}}$ & 116 & $<0.0001$ & N/A & N/A & N/A \\
\hline \multicolumn{11}{|c|}{${ }^{\mathrm{a}-\mathrm{c}}$ Means within a row without common superscripts differ $(P \leq 0.05)$. } \\
\hline $\begin{array}{l}{ }^{1} \mathrm{~A} \text { total of } 360 \text { particle size } \\
\text { grain type were then analyzed } \\
{ }^{2} \text { Orthogonal contrasts inclu } \\
{ }^{3} \text { Orthogonal contrasts inclu }\end{array}$ & $\begin{array}{l}\text { lalytical pr } \\
\text { ing } 5 \text { diffe } \\
\text { led sieving } \\
\text { led sieving }\end{array}$ & $\begin{array}{l}\text { ocedures } \mathrm{W} \\
\text { rent variati } \\
\text { time of } 1 \\
\text { time of } 1\end{array}$ & $\begin{array}{l}\text { ere conduc } \\
\text { ns of the A } \\
\text { vs. } 15 \mathrm{mi} \\
\text { vs. } 15 \mathrm{mi}\end{array}$ & $\begin{array}{l}\text { ed in this e } \\
\text { NSI/ASAE } \\
\text { n, with or } \\
\text { 1, with or }\end{array}$ & $\begin{array}{l}\text { xperiment, } \\
\text { S319.4 st } \\
\text { without sie } \\
\text { without sie }\end{array}$ & $\begin{array}{l}\text { with } 18 \mathrm{~s} \\
\text { ndard par } \\
\text { ve agitato } \\
\text { ve agitato }\end{array}$ & $\begin{array}{l}\text { mples each } \\
\text { icle size an } \\
\text { rs and with } \\
\text { rs and with }\end{array}$ & $\begin{array}{l}\text { of corn, sorghu } \\
\text { alysis method. } 1 \\
\text { or without dis } \\
\text { or without dis }\end{array}$ & $\begin{array}{l}\text { um, and wheat. St } \\
\text { There were } 4 \text { repl } \\
\text { spersion agent. } \\
\text { spersion agent. }\end{array}$ & $\begin{array}{l}\text { ubsamples of each } \\
\text { licates per method. }\end{array}$ \\
\hline
\end{tabular}

Woodworth et al. (2001) explained that the sieve agitators assisted in the movement of particles through the sieve openings by preventing the buildup on the sieves and increasing the likelihood of passage of the particles to the next sieve, without breaking the particles into smaller pieces or forcing particles through the sieve. Woodworth et al. (2001) and Stark and Chewning (2012) both described the type and number of sieve agitators used in their respective analysis procedures.

In agreement with the results of this experiment, Goodband et al. (2006), Fahrenholz et al. (2010), and Stark and Chewning (2012) also reported decreased $d_{\mathrm{gw}}$ and increased $\mathrm{S}_{\mathrm{gw}}$ with the use of sieve agitators and dispersion agent in ground corn samples. Fahrenholz et al. (2010) evaluated the sieving method using the following options: sieve shaker, sieve agitators, dispersion agent, and sieving time. Fahrenholz et al. (2010) determined that a sieving time of $15 \mathrm{~min}$ resulted in the lowest $\mathrm{d}_{\mathrm{gw}}$ and greatest $\mathrm{S}_{\mathrm{gw}}$, whereas the option without sieve agitators resulted in the highest $\mathrm{d}_{\mathrm{gw}}$ and the lowest $\mathrm{S}_{\mathrm{gw}}$. Fahrenholz et al. (2010) reported $74 \mu \mathrm{m}$ (560 to $486 \mu \mathrm{m})$ decrease with dispersion agent, $101 \mu \mathrm{m}$ (624 to $523 \mu \mathrm{m})$

Table 4. Main effect of grain type on geometric mean diameter $\left(\mathrm{d}_{\mathrm{gw}}\right)$ and geometric standard deviation $\left(\mathrm{S}_{\mathrm{gw}}\right)$ of grain types ${ }^{1}$

\begin{tabular}{lccccc}
\hline \hline Item & Corn & Sorghum & Wheat & SEM & $P$ \\
\hline $\mathrm{d}_{\mathrm{gw}}, \mu \mathrm{m}$ & $529^{\mathrm{c}}$ & $545^{\mathrm{b}}$ & $649^{\mathrm{a}}$ & 223 & $<0.0001$ \\
$\mathrm{~S}_{\mathrm{gw}}$ & & & & & \\
ASAE S319.2 & $2.36^{\mathrm{b}}$ & $2.40^{\mathrm{a}}$ & $2.35^{\mathrm{b}}$ & 0.32 & 0.025 \\
ANSI/ASAE S319.4, $\mu \mathrm{m}$ & $487^{\mathrm{b}}$ & $492^{\mathrm{b}}$ & $572^{\mathrm{a}}$ & 116 & $<0.0001$ \\
\hline
\end{tabular}

${ }^{\mathrm{a}-\mathrm{c}}$ Means within a row without common superscripts $\operatorname{differ} P \leq 0.05$.

${ }^{1}$ A total of 360 particle size analytical procedures were conducted in this experiment, with 18 samples each of corn, sorghum, and wheat. Subsamples of each grain type were then analyzed using 5 different variations of the ANSI/ASAE S319.4 standard particle size analysis method. There were 4 replicates per method. decrease when using sieve agitators, and $42 \mu \mathrm{m}$ (523 to $481 \mu \mathrm{m})$ decrease when sieving time was increased from 10 to $15 \mathrm{~min}$ for particle size analysis. Goodband et al. (2006) noted a consistent $80 \mu \mathrm{m}$ decrease in $\mathrm{d}_{\mathrm{gw}}$ with the use of dispersion agent in samples ranging from 400 to $1000 \mu \mathrm{m}$ with strong evidence that the magnitude of difference between the 2 procedures increased as $\mathrm{S}_{\mathrm{gw}}$ of the sample increased. Stark and Chewning (2012) observed $76 \mu \mathrm{m}$ (554 to $478 \mu \mathrm{m}), 49 \mu \mathrm{m}$ (659 to $610 \mu \mathrm{m})$, and $54 \mu \mathrm{m}$ (886 to $832 \mu \mathrm{m})$ decreases when using sieve agitators and decreases of $149 \mu \mathrm{m}$ (554 to $329 \mu \mathrm{m}), 203 \mu \mathrm{m}(659$ to $407 \mu \mathrm{m})$, and $184 \mu \mathrm{m}$ (886 to $648 \mu \mathrm{m}$ ) when using a dispersion agent on fine, medium, and coarse hammermill ground corn, respectively. Thus, Stark and Chewning (2012) concluded that the addition of a dispersion agent better estimated $\mathrm{d}_{\mathrm{gw}}$ and $\mathrm{S}_{\mathrm{gw}}$ than the addition of sieve agitators.

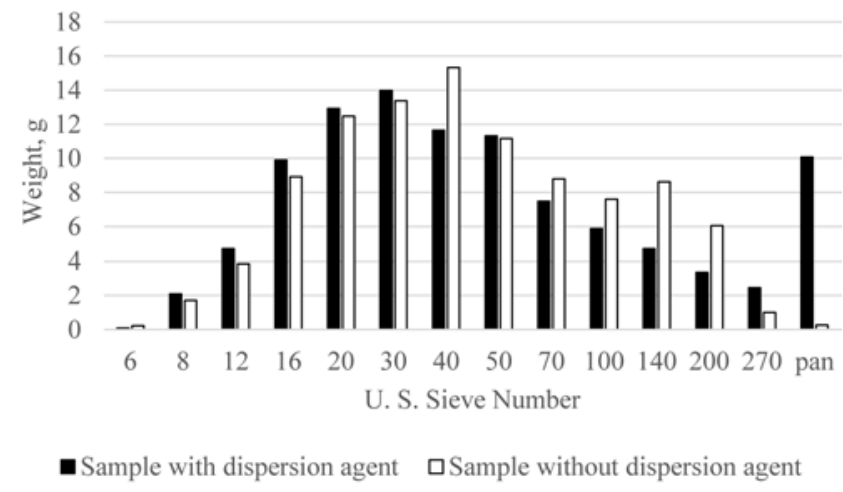

Figure 1. Particle size distribution graph of a hammer mill ground corn sample with and without the addition of a dispersion agent. For the sample with a dispersion agent, $\mathrm{d}_{\mathrm{gw}}$ is $402 \mu \mathrm{m}$, Sgw calculated using standard ASAE S319.2 (ASABE, 1995) is 3.11, and Sgw calculated using standard ANSI/ASAE S319.4 (ASABE, 2008) is $561 \mu \mathrm{m}$. For the sample without a dispersion agent, dgw is $448 \mu \mathrm{m}$, Sgw calculated using standard ASAE S319.2 is 2.50 , and Sgw calculated using ANSI/ASAE S319.4 is $470 \mu \mathrm{m}$. 
Table 5. Pearson correlation coefficients for geometric mean diameter $\left(\mathrm{d}_{\mathrm{gw}}\right)$ and geometric standard deviation $\left(\mathrm{S}_{\mathrm{gw}}\right)$ using the means and data from the method with 10-min sieving time with sieve agitators and dispersion agent compared to when dispersion agent was subtracted from the weight of the pan ${ }^{1}$

\begin{tabular}{|c|c|c|c|c|c|c|}
\hline \multirow{3}{*}{$\frac{\text { Item }}{\text { Sieve agitator inclusion }}$} & \multicolumn{6}{|c|}{ Grain type } \\
\hline & \multicolumn{2}{|c|}{ Corn } & \multicolumn{2}{|c|}{ Sorghum } & \multicolumn{2}{|c|}{ Wheat } \\
\hline & Yes & No & Yes & No & Yes & No \\
\hline $\mathrm{d}_{\mathrm{gw}}, \mu \mathrm{m}$ & 511 & 517 & 519 & 526 & 644 & 653 \\
\hline \multicolumn{7}{|c|}{ Pearson correlation coefficient } \\
\hline$P$ & \multicolumn{2}{|c|}{$<0.0001$} & \multicolumn{2}{|c|}{$<0.0001$} & \multicolumn{2}{|c|}{$<0.0001$} \\
\hline $\mathrm{r}$ & \multicolumn{2}{|c|}{1.0000} & \multicolumn{2}{|c|}{1.0000} & \multicolumn{2}{|c|}{1.0000} \\
\hline \multicolumn{7}{|l|}{$\mathrm{S}_{\mathrm{gw}}$} \\
\hline ASAE S319.2 & 2.67 & 2.63 & 2.66 & 2.62 & 2.52 & 2.48 \\
\hline \multicolumn{7}{|c|}{ Pearson correlation coefficient } \\
\hline$P$ & \multicolumn{2}{|c|}{$<0.0001$} & \multicolumn{2}{|c|}{$<0.0001$} & \multicolumn{2}{|c|}{$<0.0001$} \\
\hline$r$ & \multicolumn{2}{|c|}{0.9995} & \multicolumn{2}{|c|}{0.9994} & \multicolumn{2}{|c|}{0.9993} \\
\hline ANSI/ASAE S319.4, $\mu \mathrm{m}$ & 564 & 559 & 557 & 546 & 627 & 614 \\
\hline \multicolumn{7}{|c|}{ Pearson correlation coefficient } \\
\hline$P$ & \multicolumn{2}{|c|}{$<0.0001$} & \multicolumn{2}{|c|}{$<0.0001$} & \multicolumn{2}{|c|}{$<0.0001$} \\
\hline$r$ & \multicolumn{2}{|c|}{0.9997} & \multicolumn{2}{|c|}{0.9996} & \multicolumn{2}{|c|}{0.9971} \\
\hline
\end{tabular}

${ }^{1}$ A total of 360 particle size analytical procedures were conducted in this experiment, with 18 samples each of corn, sorghum, and wheat. Subsamples of each grain type were then analyzed using 5 different variations of the ANSI/ASAE S319.4 standard particle size analysis method. There were 4 replicates per method. Pearson correlation coefficients evaluated the goodness of fit for each grain compared to when the weight of the dispersion agent was subtracted from the pan weight for the method with a 10-min sieve time with sieve agitators and dispersion agent.

The method for calculating $\mathrm{S}_{\mathrm{gw}}$ of samples was changed between ASAE S319.2 and ANSI/ASAE S319.3. ANSI/ASAE S319.4 used the method described in ANSI/ASAE S319.3. Although the method to calculate $\mathrm{S}_{\mathrm{gw}}$ changed, the range for $68 \%$ of the particles remained the same in both methods. There were significant differences in the main effects of method $(P \leq 0.05)$ and grain $(P>0.05)$ for $\mathrm{S}_{\mathrm{gw}}$ according to ASAE S319.2 (Table 3), calculated using Eq. [5]. The geometric standard deviation according to ANSI/ASAE S319.4, calculated using Eq. [4], was also significant for method $(P \leq 0.05)$ and grain $(P \leq$ $0.05)$. The geometric standard deviation indicates the distribution of particles throughout the sieve stack, so a greater $\mathrm{S}_{\mathrm{gw}}$ value indicates a greater distribution of particle sizes. The range for $68 \%$ of the particles describes the range within $1 \mathrm{SD}$ of $\mathrm{d}_{\mathrm{gw}}$. The range and variation of the particles increased with the use of sieve agitators and a dispersion agent because sieve agitators and dispersion agents both facilitated the movement of small particles to the pan. This led to $\mathrm{S}_{\mathrm{gw}}$ being significantly greater $(P \leq 0.05)$ when 1 or both were included in the analysis. Figure 1 illustrates the increase in range of particles facilitated by the addition of a dispersion agent on moving particles to screens with small openings with the amount in the pan $(<53 \mu \mathrm{m})$ increasing by $10 \%$. The same effect was observed throughout all samples with a dispersion agent and was further supported by an increased $\mathrm{S}_{\mathrm{gw}}$.

The geometric standard deviation increased 0.39 (2.23 to 2.62) according to standard S319.2 and $94 \mu \mathrm{m}$
(485 to $579 \mu \mathrm{m}$ ) according to standard S319.4 $(P \leq 0.05)$ when the dispersion agent was included with 10-min sieving time. With 15-min sieving time, $\mathrm{S}_{\mathrm{gw}}$ increased 0.36 (2.27 to 2.63) according to standard S319.2 and $80 \mu \mathrm{m}(487$ to $567 \mu \mathrm{m})$ according to standard S319.4 $(P \leq 0.05)$. However, there was no significant change in $\mathrm{S}_{\mathrm{gw}}$ according to standard S319.2 or S319.4 when sieving time increased from 10 to $15 \mathrm{~min}$. Fahrenholz et al. (2010) reported the addition of sieve agitators increased $\mathrm{S}_{\mathrm{gw}}$ according to ASAE S319.2 by 0.40 (2.00 to 2.40), a dispersion agent increased it by 0.36 (2.10 to 2.46), and a 0.16 (2.40 to 2.56) increase when sieving time was increased from 10 to $15 \mathrm{~min}$. Goodband et al. (2006) reported that the addition of a dispersion agent also increased $\mathrm{S}_{\mathrm{gW}}$, calculated using ASAE S319.2, significantly $(P \leq 0.05)$ in samples with a $\mathrm{d}_{\mathrm{gw}}$ of 400 to $1000 \mu \mathrm{m}$.

Because of the difference in how $\mathrm{S}_{\mathrm{gw}}$ was calculated in the current study, the differences among the grain types changed. The geometric standard deviation according to ASAE S319.2 resulted in corn (2.36) and wheat (2.35) being similar but significantly different from sorghum $(2.40 ; P \leq 0.05)$. However, when $\mathrm{S}_{\mathrm{gw}}$ was evaluated using ANSI/ASAE S319.4, corn $(487 \mu \mathrm{m})$ and sorghum $(492 \mu \mathrm{m})$ were similar but different from wheat $(572 \mu \mathrm{m} ; P \leq 0.05)$.

Pearson correlation coefficients compared the goodness of fit for $\mathrm{d}_{\mathrm{gW}}$ and $\mathrm{S}_{\mathrm{gw}}$ for each grain to when $\mathrm{d}_{\mathrm{gw}}$ and $\mathrm{S}_{\mathrm{gw}}$ were calculated by subtracting the weight of dispersion agent from the weight of the pan (Table 5). For the reported means in the current study, the dispersion agent was not subtracted from the weight of the 
pan, as described in ANSI/ASAE S319.4. All of the dispersion agent was verified in the current study to reach the pan with $99.7 \%$ recovery $(n=3)$. Still, debate remained regarding whether $\mathrm{d}_{\mathrm{gw}}$ and $\mathrm{S}_{\mathrm{gw}}$ were significantly different when the weight of the dispersion agent was subtracted vs. when it was not subtracted from the weight of the pan. Correlations were evaluated using the means and data from the method with the 10-min sieving time with sieve agitators and dispersion agent. All grain types were highly correlated for $\mathrm{d}_{\mathrm{gw}}(P \leq$ $0.05 ; r=1.0000), \mathrm{S}_{\mathrm{gw}}$ using standard $\mathrm{S} 319.2(P \leq 0.05$; $r>0.9993)$, and $\mathrm{S}_{\mathrm{gw}}$ using standard $319.4(P \leq 0.05$; $r>0.9971)$, with corn having the highest correlation (Table 5). Differences for $d_{g w}$ were 6, 7, and $9 \mu \mathrm{m}$ for corn, sorghum, and wheat, respectively. Differences for $\mathrm{S}_{\mathrm{gw}}$ using standard S319.2 were 0.04 for corn, sorghum, and wheat. Differences for $\mathrm{S}_{\mathrm{gw}}$ using standard S319.4 were 5,11 , and $13 \mu \mathrm{m}$ for corn, sorghum, and wheat, respectively. The minor change in the $\mathrm{d}_{\mathrm{gw}}$ results of this study supports the current recommendation in the standard to not subtract the dispersion agent from the pan.

The results of this experiment present a challenge for feed and animal industries when comparing particle size research without knowing the method used to determine $\mathrm{d}_{\mathrm{gw}}$. The increase in sieving time (10 to $15 \mathrm{~min}$ ) that occurred in ANSI/ASAE S319.3 (ASABE, 2007) was not widely adopted by the feed industry. Furthermore, recent scientific publications (Pacheco et al., 2014; Paulk et al., 2015; Xu et al., 2015) reported the use of a 10 -min sieving time. With the exception of Fahrenholz et al. (2010), all known reported particle size data have used a sieving time of $10 \mathrm{~min}$. A literature review by Goodband et al. (2006) did not find reports or an indication that a dispersion agent was used when reporting $\mathrm{d}_{\mathrm{gw}}$ of ground grain types used in swine research studies on the effect of particle size reduction. Although past research on animal performance has not reported the use of a dispersion agent, recent scientific publications have reported the use of dispersion agent in particle size analysis (De Jong et al., 2012; Pacheco et al., 2014; Xu et al., 2015). Woodworth et al. (2001), Goodband et al. (2006), and Stark and Chewning (2012) described the type and arrangement of sieve agitators used in their respective analytical methods research. However, De Jong et al. (2012) and $\mathrm{Xu}$ et al. (2015) were among the first researchers to report the use of sieve agitators used in animal research trials. As in the findings of Goodband et al. (2006), the number, type, and arrangement of the agitators on the sieves are not typically reported in animal research studies related to particle size.

\section{LITERATURE CITED}

ASABE. 1995. Standard ASAE S319.2: Method of determining and expressing fineness of feed materials by sieving. Am. Soc. Agric. Biol. Eng., St. Joseph, MI.

ASABE. 2007. Standard ANSI/ASAE S319.3: Method of determining and expressing fineness of feed materials by sieving. Am. Soc. Agric. Biol. Eng., St. Joseph, MI.

ASABE. 2008. Standard ANSI/ASAE S319.4: Method of determining and expressing fineness of feed materials by sieving. Revised in 2012. Am. Soc. Agric. Biol. Eng., St. Joseph, MI.

De Jong, J., M. D. Tokach, L. J. McKinney, J. M. DeRouchey, R. D. Goodband, J. L. Nelssen, and S. S. Dritz. 2012. Effects of corn particle size, complete diet grinding, and diet form on finishing pig growth performance, caloric efficiency, carcass characteristics, and economics In: Kansas State University Swine Day Report 2012. Rep. Prog. No. WRP1074. Kansas State Univ., Manhattan. p. 316-324.

Fahrenholz, A. C., L. J. McKinney, C. E. Wurth, and K. C. Behnke. 2010. The importance of defining the method in particle size analysis by sieving. In: Kansas State University Swine Day Report 2010. Rep. Prog. No. WRP1030. Kansas State Univ., Manhattan. p. 261-264.

Goodband, R. D., W. Diederich, S. S. Dritz, M. D. Tokach, J. M. DeRouchey, and J. L. Nelssen. 2006. Comparison of particle size analysis of ground grain with, or without, the use of a flow agent In: Kansas State University Swine Day Report 2006. Rep. Prog. No. WRP966. Kansas State Univ., Manhattan. p. 163-168.

Pacheco, W. J., C. R. Stark, P. R. Ferket, and J. Brake. 2014. Effects of trypsin inhibitor and particle size of expeller-extracted soybean meal on broiler live performance and weight of gizzard and pancreas. Poult. Sci. 93:2245-2252. doi:10.3382/ps.2014-03986

Paulk, C. B., J. D. Hancock, A. C. Fahrenholz, J. M. Wilson, L. J. McKinney, K. C. Benhke, and J. C. Nietfeld. 2015. Effects of feeding cracked corn to nursery and finishing pigs. J. Anim. Sci. 93:1710-1720. doi:10.2527/jas.2014-8600

Stark, C. R., and C. G. Chewning. 2012. The effect of sieve agitators and dispersing agent on the method of determining and expressing fineness of feed materials by sieving. Anim. Prod. Sci. 52:69-72. doi:10.1071/AN11124

Wondra, K. J., J. D. Hancock, K. C. Behnke, and C. R. Stark. 1995. Effects of mill type and particle size uniformity on growth performance, nutrient digestibility, and stomach morphology on finishing pigs. J. Anim. Sci. 73:2564-2573. doi: $10.2527 / 1995.7392564 x$

Woodworth, J. C., R. D. Goodband, M. D. Tokach, S. S. Dritz, and J. L. Nelssen. 2001. Influence of different equipment protocols on particle size determination of ground corn. In: Kansas State University Swine Day Report 2001. Rep. Prog. No. WRP880. Kansas State Univ., Manhattan. p. 135-137.

Woodworth, J. C., A. L. Baldridge, T. L. Stainbrook, M. D. Tokach, J. L. Nelssen, R. D. Goodband, and S. S. Dritz. 2002. A comparison of different particle size analysis techniques. J. Anim. Sci. 80(Suppl. 2):104. (Abstr.)

Xu, Y., C. R. Stark, P. R. Ferket, C. M. Williams, S. Auttawong, and J. Brake. 2015. Effects of dietary coarsely ground corn and litter type on broiler live performance, litter characteristics, gastrointestinal tract development, apparent ileal digestibility of energy and nitrogen, and intestinal morphology. Poult. Sci. 94:353-361. doi:10.3382/ps/peu016 